\title{
THE Role of PROPHYLACTIC CHEST PHYSIOTHERAPY AFTER CARDIAC VALVULAR SURGERY: Is THERE ONE?
}

This work was approved by the University of the Witwatersrand in partial fulfilment of the degree of Master of Science in Physiotherapy.

\begin{abstract}
A study was conducted to investigate whether there is a role for prophylactic chest physiotherapy inipreventing pulmonary complications in-patients undergoing uncomplicated cardiac valvular surgery. 'Thirty patients were randomly divided into two groups. The patients in group $l(n=14)$ received instructions that they should cough

DE CHARMOY SB, MSc ; EALES CJ, PhD

'Department of Physiotherapy, University of the Witwatersrand after their operation and that they should get out of bed on the second post-operative day. The patients in group 2 $(n=16)$ were seen pre-operatively and treated post-operatively by a physiotherapist. The treatment consisted of breathing exercises, supported coughing and assistance with walking from the second post-operative day. These patients were seen twice daily on the first and second post-operative days and once daily on the third and fourth post-operative days. No patients in either group developed a pulmonary complication during their post-operative hospital stay. The incidence of hypoxaemia, chest $X$-ray abnormalities and length of post-operative stay were not significantly higher for the control group. The findings of this study suggest that the role of prophylactic chest physiotherapy following cardiac valvular surgery is questionable.
\end{abstract}

\section{KEYWORDS: PHYSICAL THERAPY, PHYSIOTHERAPY, BREATHING EXERCISES, OPEN HEART SURGERY}

\section{INTRODUCTION}

Physiotherapists working in the cardiothoracic wards spend a large proportion of time each day assessing and treating post-operative cardiac patients. In the last two decades, much research into different combinations of chest physiotherapy treatment techniques has occurred in an attempt to establish the most effective combination in preventing post-operative pulmonary complications. Recent research has compared specific chest physiotherapy regimes to a programme of walking the patients as soon as possible post-operatively (Jenkins et al, 1989; Jenkins et al, 1990; Stiller et al, 1994; Stiller et al, 1995). The research by Jenkins and Stiller has been largely confined to patients undergoing coronary

\section{CORRESPONDENCE:}

Sue de Charmoy

Physiotherapy Department

University of the Witwatersrand

7 York Road Parktown 2193

Johannesburg South Africa

Tel: (27) 11 488-3450

Fax: (27) 11 488-3450

Email: 159suz@chiron.wits.ac.za artery bypass graft surgery. These researchers have consistently reported that prophylactic physiotherapy in this patient population is of little value in preventing post-operative pulmonary complications. It must be emphasised at this point that the patients in all these studies were either mobilised by the nursing staff or given an instruction to mobilise.

Jenkins et al (1994) reported the incidence of respiratory complications postoperatively as $9 \%$ despite the lack of chest physiotherapy. The patients excluded from this study included those who had had previous coronary artery surgery or pulmonary surgery, and those that had a pre-operative respiratory abnormality. In 1995 Stiller et al. investigated whether the incidence of clinically significant pulmonary complications had increased since the recommendation that routine post-operative physiotherapy was not necessary in the uncomplicated coronary artery surgery patient. The 1995 study included all patients undergoing heart surgery requiring cardiopulmonary bypass. The only difference in this study from the 1994 study was that it included 13 patients who had undergone cardiac valve surgery without coronary artery surgery. Clinically significant pulmonary complications were found in $7.1 \%$ (nine out of 127 patients) of the total patient population. Án important consideration im this study is that all patients undergoing cardiac surgery were included and thus patients with significant pre-operative risk factors were also included.

A study by Johnson et al (1996) included 75 patients who had undergone ,valve surgery. The mean age of the patients in this study group was $63 \pm 12$ and $68 \pm 10$ years. The patients were randomly divided into two groups. One group received a lower intensity treatment which included education, early ambulation, and deep breathing exercises, while the other group received the same treatment with the addition of single handed percussion (higher intensity treatment). They reported a 5\% respiratory complication rate. For the purposes of their study a respiratory complication (pneumonia) was defined as the presence of three out of four of the following variables: a white blood cell count greater than $10^{9} / \mathrm{L}$; an oral temperature greater than $38.5^{\circ} \mathrm{C}$; a positive culture for a respiratory pathogen in the sputum and evidence of air bronchograms on chest X-ray. 
In South Africa the population encountered who undergo valve surgery is markedly different to that of the first world due to the prevalence of rheumatic heart disease. In South Africa a study conducted in 1972 by McLaren et al. surveyed 12050 black schoolchildren in Soweto. They found an overall prevalence rate of rheumatic heart disease of 6.9 per 1000 with a peak rate of 19.2 per 1000 in children aged 15 to 18 years (McLaren et al, 1975). The incidence of rheumatic heart disease has been on the decline in the developed world for many years. The decline is evident in the following statistics for the United States of America. In 1950 the death rate per 100000 was 14 and in 1993 it was 1.7 per 100000 (American Heart Association, 1997).

In South Africa patients with rheumatic valve disease, especially those presenting with active carditis, are young, black and have relatively underprivileged backgrounds (McLaren et al, 1975; Barlow 1992a and 1992b; Marcus et al, 1994). In the year 1 June 1994 to 31 May 1995, 313 patients underwent cardiac valve surgery at the Johannesburg hospital. There were 239 black, 27 white, 14 asian and 33 patients of mixed racial descent. Of these 182 were female and 131 male. Seventy-six of these patients were under the age of 15 .

In contrast, during the same period, 118 patients underwent coronary artery surgery, thus indicating the need for research involving these valvular surgery patients. It was bearing this in mind that a study was conducted to determine if the results obtained by Stiller et al (1994 and 1995), Jenkins et al (1989 and 1994) and Johnson et al (1996), could be applied to the South African valve surgery population.

\section{METHODS}

The research hypothesis for this study was that routine post-operative physiotherapy, which includes a regimen of breathing exercises, coughing and walking, is of no benefit in the uncomplicated post-operative valvular surgery patient.

\section{Subjects}

All patients admitted for elective cardiac valvular surgery over a three-month

Table 1. Individual patient data for patients in the group 1.

\begin{tabular}{|l|l|l|l|l|l|}
\hline Patient & Age & Sex & Height (m) & Weight (Kg) & BMI (Kg/m $\left.{ }^{2}\right)$ \\
\hline 1 & 29 & $F$ & 1.54 & 67.30 & 28.38 \\
\hline 7 & 50 & $F$ & 1.54 & 57.00 & 24.03 \\
\hline 9 & 11 & $F$ & 1.26 & 22.50 & 14.17 \\
\hline 11 & 26 & $F$ & 1.59 & 50.20 & 19.86 \\
\hline 13 & 12 & $F$ & 1.39 & 30.10 & 15.58 \\
\hline 15 & 35 & $F$ & 1.58 & $67: 80$ & 27.26 \\
\hline 16 & 38 & $F$ & 1.55 & 80.50 & 33.51 \\
\hline 19 & 25 & $F$ & 1.64 & 65.30 & 24.28 \\
\hline 20 & 22 & $F$ & 1.44 & 50.20 & 24.21 \\
\hline 21 & 29 & $F$ & 1.56 & 43.00 & 17.67 \\
\hline 28 & 40 & $F$ & 1.51 & 49.80 & 21.99 \\
\hline 29 & 15 & $F$ & 1.54 & 46.20 & 19.48 \\
\hline 31 & 30 & M & 1.61 & 53.80 & 20.76 \\
\hline 32 & 36 & $F$ & 1.56 & 54.70 & 22.48 \\
\hline Mean & 28.43 & & 1.52 & 52.74 & 22.4 \\
\hline S.D & \pm 11.12 & & \pm 0.09 & \pm 0.09 & \pm 5.16 \\
\hline
\end{tabular}

- S.D. = Standard deviation

Table 2. Individual patient data for patients in group 2.

\begin{tabular}{|l|l|l|c|c|c|}
\hline Patient & Age & Sex & Height $(\mathrm{m})$ & Weight $(\mathrm{Kg})$ & BMl $\left(\mathrm{Kg} / \mathrm{m}^{2}\right)$ \\
\hline 3 & 16 & $\mathrm{~F}$ & 1.28 & 39.70 & 24.23 \\
\hline 4 & 13 & $\mathrm{M}$ & 1.38 & 29.10 & 15.28 \\
\hline 5 & 44 & $\mathrm{~F}$ & 1.60 & 84.20 & 32.89 \\
\hline 6 & 11 & $\mathrm{M}$ & 1.26 & 22.00 & 13.86 \\
\hline 8 & 53 & $\mathrm{~F}$ & 1.60 & 50.30 & 19.65 \\
\hline 12 & 42 & $\mathrm{~F}$ & 1.67 & 70.70 & 25.35 \\
\hline 17 & 23 & $\mathrm{~F}$ & 1.63 & 52.20 & 19.65 \\
\hline 18 & 12 & $\mathrm{M}$ & 1.34 & 25.60 & 14.26 \\
\hline 22 & 32 & $\mathrm{~F}$ & 1.55 & 44.10 & 18.36 \\
\hline 23 & 40 & $\mathrm{M}$ & 1.54 & 48.00 & 20.24 \\
\hline 25 & 63 & $\mathrm{M}$ & 1.84 & 85.60 & 25.28 \\
\hline 26 & 23 & $\mathrm{M}$ & 1.76 & 67.40 & 21.76 \\
\hline 27 & 40 & $\mathrm{~F}$ & 1.60 & 48.30 & 18.87 \\
\hline 30 & 33 & $\mathrm{M}$ & 1.64 & 61.90 & 23.16 \\
\hline 33 & 24 & $\mathrm{~F}$ & 1.58 & 44.20 & 17.71 \\
\hline 34 & 27 & $\mathrm{M}$ & 1.72 & 56.00 & 18.93 \\
\hline Mean & 31 & & 1.56 & 51.83 & 20.59 \\
\hline S.D. & \pm 15.21 & & \pm 0.17 & \pm 18.79 & $\pm 4.84 *$ \\
\hline
\end{tabular}

- S.D. = Standard deviation

period who signed informed consent were considered for inclusion in the study. A total of 36 patients out of 38 admissions were included. Patients excluded pre-operatively were those with a documented history of pulmonary disease or a neurological disorder which interfered with their ability to participate in the study. Two patients were excluded from the study pre-operatively as a result of a documented history of pulmonary tuberculosis. Post-operatively patients were withdrawn from the study if they were intubated for a period longer than 24 hours, had an intensive care stay of longer than 48 hours or returned from theatre with a neurological or cardiac complication which rendered them unstable or unable to participate in the study.

Six patients were withdrawn from the study during the post-operative period. Three of the patients suffered a cerebrovascular accident during surgery or in the 
immediate post-operative period, one patient was intubated for longer than 24 hours and the other two patients remained in the intensive care unit for longer than 48 hours due to cardiac instability.

The total study population was 30 patients of which 21 were females and nine males. The mean age of the group was 29.72 years.

\section{Groups}

Participants were allocated a number in order of admission. These numbers were then randomly assigned to either group one or two pre-operatively. Thus prior to the pre-operative interview the researcher knew whether the patient would be in group 1 (control group) or group 2 (treatment group). Each patient was interviewed 24 to 48 hours preoperatively.

\section{Group 1}

At the pre-operative interview the patients in group 1 were instructed that they should try and cough regularly. In addition to coughing, they should, together with the help of the nursing staff, get out of bed and walk around the ward on the second post-operative day. They were informed that a physiotherapist and the medical staff throughout their post-operative hospital stay would routinely assess them.

\section{Group 2}

The patients in group 2 were also interviewed pre-operatively and they were instructed that they would be seen daily after their operation.

These patients received their first physiotherapy treatment after extubation. Physiotherapy consisted of the patient in supine with a minimum of 45 degrees head and trunk elevation. The physiotherapist taught the patient lateral costal expansion exercises followed by a passive expiration and a rib spring at the end of expiration to stimulate a deep inspiration at the first post-operative treatment session.' The patients were also taught supported coughing using a pillow against the incision site. The combination of breathing and coughing exercises were continued until the physiotherapist assessed the chest as clinically clear on auscultation (good breath sounds and no adventitious sounds), and an effective unproductive cough was present.

The above treatment was carried out twice on post-operative days one and two and once on days three and four. From day two the patients were walked around the ward (45 meters) at each treatment session. The patients were also allowed to walk to the bathroom as required.

\section{Measurements}

Pre-operatively, each patient's age, gender, racial group, height (in meters) and weight (in kilograms) were recorded and the body mass index calculated. Past medical and surgical history, smoking history, present history and pre-operative medication were also ascertained.

Smoking histories were recorded as pack-years ((number of years smoked $x$ number of cigarettes per day) / 20) and the length of smoking cessation was recorded for those patients who had stopped smoking.

Oral temperatures and respiratory rates were recorded pre-operatively and on days one to four post-operatively. The 06h00 temperature was recorded from the medical record and the respiratory rate was counted over one full minute prior to the physiotherapy treatment. Earlobe capillary blood (Spiro and Dowdeswell, 1976) was taken preoperatively and on days one and four post-operatively. All measurements were done with the patient in long sitting in bed and breathing room air. If the patients were on supplemental oxygen this was discontinued for 15 minutes prior to earlobe capillary blood gas sampling. For the patients in the group 2 the blood gases were sampled one hour after the morning physiotherapy treatment. Blood gases were analysed using a Ciba-Corning 288 blood gas system machine. The partial pressure of oxygen " in arterial blood $\left(\mathrm{PaO}_{2}\right)$, the partial pres- " sure of carbon dioxide in arterial blood $\left(\mathrm{PaCO}_{2}\right)$ and the percentage saturation were recorded. From this the alveolar arterial oxygen difference $\left(\mathrm{P}(\mathrm{A}-\mathrm{a}) \mathrm{O}_{2}\right)$ was calculated.

Chest X-rays were taken pre-operatively, and on days one, two and four post-operatively. The chest $\mathrm{X}$-rays were scored by a radiologist who was blind to the composition of the patient groups. The X-ray score was calculated in the following way. Each lung was scored individually and then the totals were added together. The location and type of abnormality was recorded and the presence of pleural effusions was documented. The scores were allocated as follows: 0, no abnormalities were noted and the lung fields were assessed to be radiologically clear, 3 , minor collapse / consolidation at one base, involving 1-3 bronchopulmonary segments, 7, pronounced collapse / consolidation and / or both at one base involving an entire lobe, 15, bilateral collapse and / or consolidation and / or patchy infiltrates were noted.

The researcher noted the length of post-operative stay in hospital and the incidence of pulmonary complications (as defined by the criteria below). For the purposes of this study a pulmonary complication was defined as: a temperature greater than 38.5 degrees Celsius, radiological evidence of consolidation or collapse and evidence of respiratory infection clinically and on auscultation as decided by the cardiothoracic surgeon.' The presence of all three of these criteria were required in order to diagnose a pulmonary complication. The cardiothoracic surgeon was unaware as to which group the patient was in.

\section{Statistics}

The data collected was statistically analysed using the Mann-Whitney sum test, the Wilcoxin test and the chi-square test. Means, standard deviations and frequency distributions were used to summarise the data and a $\mathrm{p}$ - value equal to or less than 0.05 was considered significant.

\section{Intra-examiner reliability}

Ten percent of the chest $\mathrm{X}$-rays were scored again by the same radiologist six weeks after the initial scoring. The second set of scores corresponded $100 \%$ with the initial set thus proving intraexaminer reliability.

\section{RESULTS}

The groups were well matched for age $(p=0.68)$, height $(p=0.16)$, weight 
Table 3. Oral temperatures, arterial blood gas analyses and chest X-ray scores.

\begin{tabular}{|c|c|c|}
\hline & Group 1 & Group 2 \\
\hline \multicolumn{3}{|l|}{ PRE-OPERATIVE } \\
\hline Temperature $\left({ }^{\circ} \mathrm{C}\right)$ & $36.44 " 0.21$ & $36.45 " 0.35$ \\
\hline Respiratory rate (breaths/min) & $16 " 7.14$ & $14.75 “ 3.51$ \\
\hline \multicolumn{3}{|l|}{ Arterial blood gases } \\
\hline $\mathrm{PaO}_{2}$ & 78.75 “16.43 & $78.32 “ 11.90$ \\
\hline$\%$ Saturation & $95.26 “ 0.83$ & $95.65 “ 2.52$ \\
\hline $\mathrm{P}(\mathrm{A}-\mathrm{a}) \mathrm{O}_{2}$ & 32.79 ״ 15.82 & $32.28 “ 11.35$ \\
\hline \multicolumn{3}{|l|}{ Chest $X$-ray scores } \\
\hline Total score & 0 & $0.19 " 0.75$ \\
\hline RLL & 0 & $0.19 " 0.75$ \\
\hline LLL & 0 & $0.19 " 0.75$ \\
\hline \multicolumn{3}{|l|}{ DAY I POST-OPERATIVE } \\
\hline Temperature $\left({ }^{\circ} \mathrm{C}\right)$ & $37.63 " 0.61$ & $37.94 " 0.52$ \\
\hline Respiralory rate (breaths/min) & $23.93 " 3.81$ & $22.81 " 5.86$ \\
\hline \multicolumn{3}{|l|}{ Arterial blood gases } \\
\hline $\mathrm{PaO}_{2}$ & $71.38 “ 17.27$ & $60.35 * 14.09$ \\
\hline$\%$ Saturation & $98.14 " 0.83$ & $95.65 " 3.63$ \\
\hline $\mathrm{P}(\mathrm{A}-\mathrm{a}) \mathrm{O}_{2}$ & $38.20 " 17.62$ & $49.13 " 14.09$ \\
\hline \multicolumn{3}{|l|}{ Chest $X$-ray scores } \\
\hline Total score & $1.5 " 2.28$ & $1.69 " 2.18$ \\
\hline RLL & $1.07 " 1.49$ & $1.13^{\prime \prime} 1.5$ \\
\hline LLL & $0.43 " 1.09$ & $0.56^{\prime \prime} 1.21$ \\
\hline \multicolumn{3}{|l|}{ DAY 4 POST-OPERATIVE } \\
\hline Temperature $\left({ }^{\circ} \mathrm{C}\right)$ & $36.84 " 0.38$ & $36.86 " 0.42$ \\
\hline Respiralory rale (breaths/min) & $22.86 " 4.62$ & $21.86 " 6.59$ \\
\hline \multicolumn{3}{|l|}{ Arterial blood gases } \\
\hline $\mathrm{PaO}_{2}$ & $58.91 " 9.27$ & $60.35 " 14.10$ \\
\hline$\%$ Saturation & $92.02 " 4.64$ & $91.98 “ 4.09$ \\
\hline $\mathrm{P}(\mathrm{A}-\mathrm{a}) \mathrm{O}_{2}$ & $53.13 " 8.83$ & $54.24 " 7.87$ \\
\hline \multicolumn{3}{|l|}{ Chest X-ray scores } \\
\hline Total score & $1.71 " 1.94$ & $2.44 " 2.25$ \\
\hline RLL & $1.5 * 1.56$ & $1.69 " 1.54$ \\
\hline LLL & $0.21 " 0.80$ & $0.75 " 1.34$ \\
\hline
\end{tabular}

All values are given as means \pm standard deviations

The number of patients in treatment group was 16 for all values and in the non-treatment group 14 for all values.

$\mathrm{RLL}$, right lower lobe, LLL, leff lower lobe, $\mathrm{PaO}_{2}$, partial pressure of oxygen in arterial blood; $\mathrm{P}(\mathrm{A}-\mathrm{a}) \mathrm{O}_{2}$, the alveolar - arterial oxygen difference calculated as follows:

$\mathrm{P}(\mathrm{A}-\mathrm{a}) \mathrm{O}_{2}=\left\{\mathrm{FIO}_{2}(620-47)-\mathrm{PaCO}_{2} / 0.8\right\}-\mathrm{PaO}_{2}$

$(\mathrm{p}=0.74)$, body mass index $(\mathrm{p}=0.28)$ and race $(p=0.23)$ (see Tables 1 and 2 ). The $\mathrm{PaO}_{2}$ was not significantly different between the groups ( $\mathrm{p}=0.68$ pre-operative, $p=0.07$ day 1 and $p=0.92$ day 4 ). This value did change significantly from its pre-operative value to its post-operative value for both groups. This significant decrease in $\mathrm{PaO}_{2}$ improved slightly from day one to day four, however a profound hypoxia was still present on day four post-operatively in all patients (Table 3).
Chest X-ray changes were also not significantly different between the groups $(p>0.05)$. There was however a significant difference $(p=0.001)$ between the pre-operative chest $\mathrm{X}$-rays and the day 1 , day 2 and day 4 chest $X$-rays for both the groups. There was no significant difference between the day 1 and day $2 \mathrm{X}$-rays $(\mathrm{p}=0.109)$, the day 1 and day $4 \mathrm{X}$-rays $(p=0.234)$ or the day 2 and day 4 chest $\mathrm{X}$-ray scores $(\mathrm{p}=.0 .1)$. The atelectasis present post-operatively was still present on day four regardless of whether the patient had had physiotherapy or not (Table 3).

The incidence of pulmonary complications was $0 \%$ as not a single patient developed a pulmonary complication as defined by the criteria in this study. The length of post-operative hospital stay was also not significantly different between the groups.

\section{DISCUSSION AND CONCLUSION}

This study showed that the incidence and severity of hypoxaemia, chest X-ray changes, pulmonary complications and length of post-operative hospital stay were not significantly different for a control group who received a pre-operative instruction and no prophylactic chest physiotherapy in patients undergoing uncomplicated cardiac valve surgery. The deleterious changes observed in arterial blood gases, chest $\mathrm{X}$-rays and temperature were not of clinical significance as no patients were diagnosed as having a post-operative pulmonary complication.

The results of this study although conducted on a smaller patient population seem to confirm the results of the Stiller et al (1994 and 1995) and Jenkins et al (1989 and 1990) studies. It would thus seem that chest physiotherapy has no role to play in the prevention of pulmonary complications after uncomplicated cardiac valvular surgery. "These results do not attempt in any way to draw conclusions for patients undergoing emergency valvular surgery or for patients with pre-existing pulmonary disease. For both these patient groups further studies will need to be conducted. In addition this study makes no attempt to define the role of physiotherapy in patients with prolonged intubation times or intensive care stays, or in those who develop post-operative neurological complications.

It is possible that the patients in group 1 , by virtue of signing informed consent and talking to patients who were being treated may have altered their post-operative behaviour. This may have acted as a confounding variable.

It would seem then that prophylactic chest physiotherapy in the post-operative valvular surgery patient is not indicated provided the patient is mobilised 
out of bed as soon as possible and instructions to cough post-operatively are given. It is possible that this change in physiotherapy practice has been bought about due to more efficient anaesthetic techniques, intra-operative and post-operative patient care. It is the recommendation of this study that physiotherapists assess all patients postoperatively. Treatment is only indicated if and when a pulmonary complication is identified.

\section{REFERENCES}

Barlow JB 1992(a) Aspects of active rheumatic carditis. Australian and New Zealand Journal 22: 592 - 600 .

Barlow JB 1992(b) Idiopathic (Degenerative) and Rheumatic Mitral Valve Prolapse: Historical Aspects and an Overview. The Journal of Heart Valve Disease 1: 163 - 174
Jenkins SC, Soutar SA, Loukota JM, Johnson LC, Moxham J 1989 Physiotherapy after coronary artery surgery: are breathing exercises necessary? Thorax 44: 634 - 639

Jenkins SC, Soutar SA, Loukota JM, Johnson LC, Moxham J 1990 A comparison of breathing exercises, incentive spirometry and mobilisation after coronary artery surgery. Physiotherapy Theory and Practice 6: 117 - 126

Johnson D, Thompson D, Mayers I 1996 The effect of physical therapy on respiratory complications following cardiac valve surgery. Chest 109: $638-644$

Marcus RH, Sareli P, Pocock WA, Barlow JB 1994 The spectrum of severe rheumatic mitral valve disease in a developing country. Correlations among clinical presentation, surgical pathologic findings, and haemodynamic sequelae. Annals of Internal Medicine 120: $177-183$.

McLaren MJ, Hawkins DM, Koornhof HJ,Bloom KR, Bramwell-Jones DM, Cohen E, Gale GE, Karnarek K, Lachman AS, Lakier JB,
Pocock WA, Barlow JB 1975 Epidemiology of rheumatic heart disease in black school children of Soweto, Johannesburg. British Medical Journal 3: 474 - 478.

Spiro SG and Dowdeswell IRG. 1976 Arterialised ear lobe blood samples for blood gas tensions. British Journal of Diseases of the Chest 70: $263-268$

Stiller K, Montarello J, Wallace M, Daff M, Grant R, Jenkins S, Hall B, Yates H 1994 Are breathing and coughing exercises necessary after coronary artery surgery? Physiotherapy Theory and Practice 10:143-152

Stiller K, Crawford R, McInnes M, Montarello J, Hall B 1995 The incidence of pulmonary complications in patients not receiving prophylactic chest physiotherapy after cardiac surgery. Physiotherapy Theory and Practice 11: $205-208$

\section{THE UK'S LEADING AGENCY FOR PHYSIOTHERAPISTS}

WORKING

IN THE UK

NEEDN'T BE

A PUZZLE

* Friendly advice on:

- State Registration

- UK entry

- Accommodation

* Widest choice of posts

* Top rates of pay

* CPSM fees reimbursed

* FREE Indemnity Insurance*

For our FREE 'Working Holidays

in Britain' brochure, contact Debi Faulder MCSP SRP MECI on

TOLL-FREE 0800-99-3055 (24 Hours)

or Fax on 09441812076894 or E-mail: locums@corinth.co.uk

*Subject to the Terms of the Policy 